Vol. 20(2011): 169-175.

\title{
Sauerkraut and sauerkraut juice fermented spontaneously using mineral salt, garlic and algae
}

\author{
Britta Wiander ${ }^{1 *}$ and Airi Palva ${ }^{2}$ \\ ${ }^{\text {I}}$ Finnish Food Safety Authority Evira, PO Box 111, FI-32201 Loimaa, Finland, \\ ${ }^{2}$ University of Helsinki, Faculty of Veterinary Medicine, PO Box 66, FI-00014 Helsingin yliopisto, Finland \\ *e-mail: britta.wiander@evira.fi
}

\begin{abstract}
The use of mineral salt in natural fermentation of white cabbage into sauerkraut and sauerkraut juice, in order to evaluate whether the amount of $\mathrm{NaCl}$ could be lowered, was studied. Mineral salt differs from ordinary salt because $\mathrm{NaCl}$ is partially replaced by $\mathrm{KCl}$. In the fermentations mineral salt was used in various amounts $(0.8-1.5 \%)$ and in combination with garlic and algae. The final $\mathrm{NaCl}$ concentrations in these fermentation trials were $0.5-0.9 \%$. Fermentations were also carried out with cabbage sliced to different degrees. The sauerkraut juice fermented by using $0.8 \%$ mineral salt $(0.5 \% \mathrm{NaCl})$ was found to have the best sensory quality. The yield of sauerkraut juice increased as the coarseness of the cabbage mix decreased.
\end{abstract}

Key-words: sauerkraut, sauerkraut juice, salt, garlic, algae and seaweed

\section{Introduction}

Fermented sauerkraut has a long history and is generally considered to be a health promoting product. Traditional sauerkraut fermentations have usually been carried out in the presence of rather high $\mathrm{NaCl}$ amounts. However, consumers who want to eat health promoting products prefer products with low sodium content.
The fermentation of white cabbage into sauerkraut traditionally proceeds in the presence of $\mathrm{NaCl}$. There are reports on using different salt concentrations (Delanoe and Emard 1971, Gangopadhyay and Mukherjee 1971, Mayer et al. 1973, Niven 1980). Low percentages of $\mathrm{NaCl}$ have been used in natural sauerkraut fermentations by Tolonen et al. 2002 and Viander et al. 2003. Sauerkraut fermentations with lowered salt percentages have also been studied by Pederson 1940, Fleming and 
Wiander, B. and Palva, A. Impact of mineral salt, garlic and algae on sauerkraut fermentation

McFeeters 1985, Trail et al. 1996, Johanningsmeier et al. 2007, Martinez-Villaluenga et al. 2009, Penas et al. 2010). Sauerkraut has been prepared utilising hydrolysed protein and a salt content of $1.0-4.5 \%$ (Hsu et al. 1984, Wedral et al. 1985). A patent has been worked out for making sauerkraut where part of the normally added salt is replaced by an alcohol/acid mixture (Owades 1991). Delclos (Delclos 1992) has studied the use of a reduced $\mathrm{NaCl}$ concentration in combination with lactic acid bacteria starter cultures, the $\mathrm{NaCl}$ concentration being $1 \%$. Kimchi is traditionally produced by using $\mathrm{NaCl}$, but there have been studies on replacing part of the $\mathrm{NaCl}$ with $\mathrm{KCl}$ (Choi et al. 1994).

In this study we have further optimised the use of mineral salt (containing $28 \% \mathrm{KCl}$ and $57 \%$ $\mathrm{NaCl}$ ) in natural fermentation of white cabbage. Various amounts of mineral salt $(0.8-1.5 \%)$ were used with final $\mathrm{NaCl}$ concentrations of $0.5-0.9 \%$. Fresh garlic was used in combination with $0.8 \%$ mineral salt. Garlic extract is known to inhibit the growth of moulds (Sutabhaha et al. 1992). Vacame algae in combination with $0.8 \%$ mineral salt were also used. It has been reported that fresh edible seaweeds can be preserved by lactic acid fermentation and that the juice may be drained off at the end of the fermentation and replaced by sauerkraut juice to improve the sensory quality (Oltz and Hubert 1990). In this study white cabbage was also cut into slices of different size and fermented using $0.8 \%$ mineral salt to study the impact of the coarseness of the cabbage on the resulting yield of sauerkraut juice.

\section{Material and methods}

\section{Fermentation trials}

In the first fermentation trial the amounts of mineral salt used were $0.8 \%, 1.2 \%$ and $1.5 \%$. The treatments were carried out in duplicate. The sliced white cabbage (cultivar Nosomi) was fermented in steel vessels. Mineral salt was mixed with the sliced cabbage, the slices were pressed tightly together and covered with a plastic film, on which water was poured to inhibit air from entering the cabbage mixture and $\mathrm{CO} 2$ from escaping from the mixture. The amount of sliced cabbage per vessel was 2.5 $\mathrm{kg}$. Fermentations were carried out at $20^{\circ} \mathrm{C}$.

In the second fermentation trial the amount of mineral salt was $0.8 \%$. Fresh domestic garlic $(0.2 \%)$ or Vacame algae from Japan $(1 \%)$ was added to the sliced cabbage (cultivar Nosomi). The treatments were carried out in duplicate. One duplicate treatment was used as a control and contained neither garlic nor algae. Mixing of the salt, pressing of the cabbage mix $(2.5 \mathrm{~kg})$ and other fermentation conditions were as described above.

In the third fermentation trial $0.8 \%$ mineral salt was used and white cabbage (cultivar Erdeno) was cut into slices of various sizes. The treatments were carried out in duplicate. The sizes of the slices were approximately: $1 \mathrm{~mm} \times 1 \mathrm{~mm}, 2 \mathrm{~mm} \times 10 \mathrm{~mm}$ and $3 \mathrm{~mm} \times 40 \mathrm{~mm}$. The sliced cabbage $(1 \mathrm{~kg})$ was fermented in glass vessels and the fermentation conditions were as described above.

Mineral salt containing $28 \% \mathrm{KCl}$ and $57 \%$ $\mathrm{NaCl}$ was used in all fermentation trials. The mineral salt (Pansuola ${ }^{\circledR}$ ) contains $57 \%$ sodium chloride, $28 \%$ potassium chloride, $12 \%$ magnesium sulphate, $2 \%$ lycine hydrochloride, $1 \%$ silicon dioxide and $0,0036 \%$ potassium iodide. The mineral salt has been produced for and marketed by Oriola Oy (Espoo, Finland).

\section{Sampling}

Samples were taken regularly during the fermentation processes by using sterile pipettes. To get representative samples, equal volumes of cabbage juice were taken from three different places in the fermentation vessels from a depth of approximately $5 \mathrm{~cm}$. The three samples were mixed into one sample. When the samples were taken the plastic film covering the cabbage mixture was partly carefully removed avoiding water from entering the cabbage mixture. 


\section{Microbiological analyses}

Lactic acid bacteria were enumerated by cultivation on M.R.S nutrition medium (Biokar Diagnostics, France or Difco Labs, USA) containing 0.02\% sodium azide and $1.5 \%$ agar for $2-3$ days at $30^{\circ} \mathrm{C}$. Yeasts and moulds were grown on Yeast extract glucose chloramphenicol agar (Difco Labs, USA) for 7 days at $25^{\circ} \mathrm{C}$. All microbiological analyses were carried out either in duplicate or triplicate.

\section{Chemical analyses}

The $\mathrm{pH}$ of the cabbage juice was measured by using a pH-meter (RadiometerPHM93, Radiometer Analytical, Denmark) during the fermentation. Total acidity, given as total lactic acid, was measured by titration using $0.1 \mathrm{~N} \mathrm{NaOH}$ with phenolphtalein as indicator. All chemical analyses were carried out either in duplicate or triplicate.

\section{Sensory evaluation}

The sensory quality of the sauerkraut juices was evaluated by a taste panel consisting of 5 trained persons. A scale of 1-5, where number 1 refers to not acceptable and number 5 to excellent taste and quality, was used in the evaluation. The quality scale of Karlsruhe was used (Tuorila and Hellemann 1993).

\section{Results}

\section{Optimisation of mineral salt concentra- tion in sauerkraut fermentation}

The decrease in $\mathrm{pH}$ was more rapid in the treatments in which $1.5 \%$ mineral salt was used compared to the $\mathrm{pH}$ drop in the treatments with $0.8 \%$ mineral salt. The titratable acidity increased more rapidly during the fermentation process when using $1.5 \%$ mineral salt (Fig. 1). In the fermentations with
Fig. 1. Change of $\mathrm{pH}$ (squares) and amount of lactic acid (triangles) during spontaneous fermentation of sauerkraut at $20^{\circ} \mathrm{C}$ using mineral salt. The symbols refer to the used mineral salt concentrations: $0.8 \%$ mineral salt $(\square \triangle), 1.5 \%$ mineral salt ( - $\boldsymbol{\Delta}$ ). Asteriks (*) refers to pressed sauerkraut juice. Mean values of two parallel samples are shown.

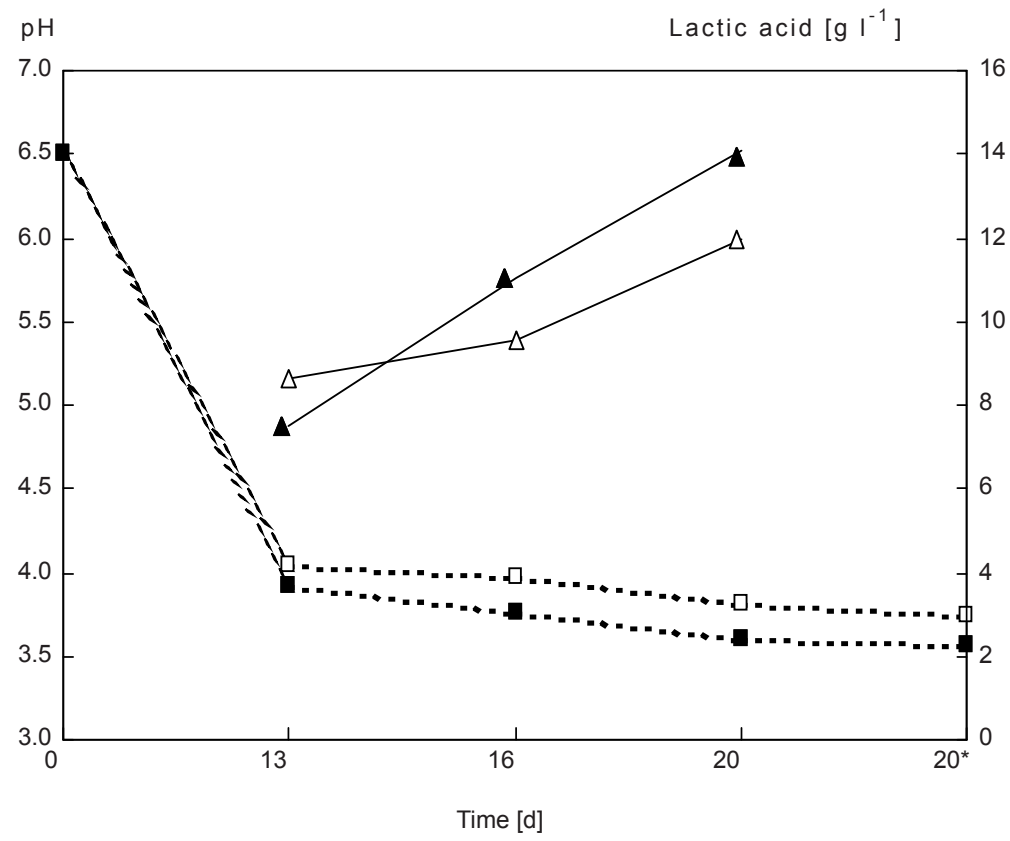


Wiander, B. and Palva, A. Impact of mineral salt, garlic and algae on sauerkraut fermentation

$0.8 \%$ and $1.2 \%$ mineral salt $\mathrm{pH}$ was similar in all pressed sauerkraut juices. In the treatments with $1.5 \%$ mineral salt the $\mathrm{pH}$ of the pressed juices was somewhat lower compared to the juices produced by fermentation with $0.8 \%$ and $1.2 \%$ mineral salt.

The number of lactic acid bacteria was highest and the number of yeasts and moulds was lowest in the fresh sauerkraut juices resulting from the treatments with $1.5 \%$ mineral salt (Fig. 2, 3).

The sensory evaluation of the sauerkraut juices showed that the best sensory quality was obtained by fermentation with $0.8 \%$ mineral salt (4-5 scores). This treatment resulted in a very smoothtasting juice.

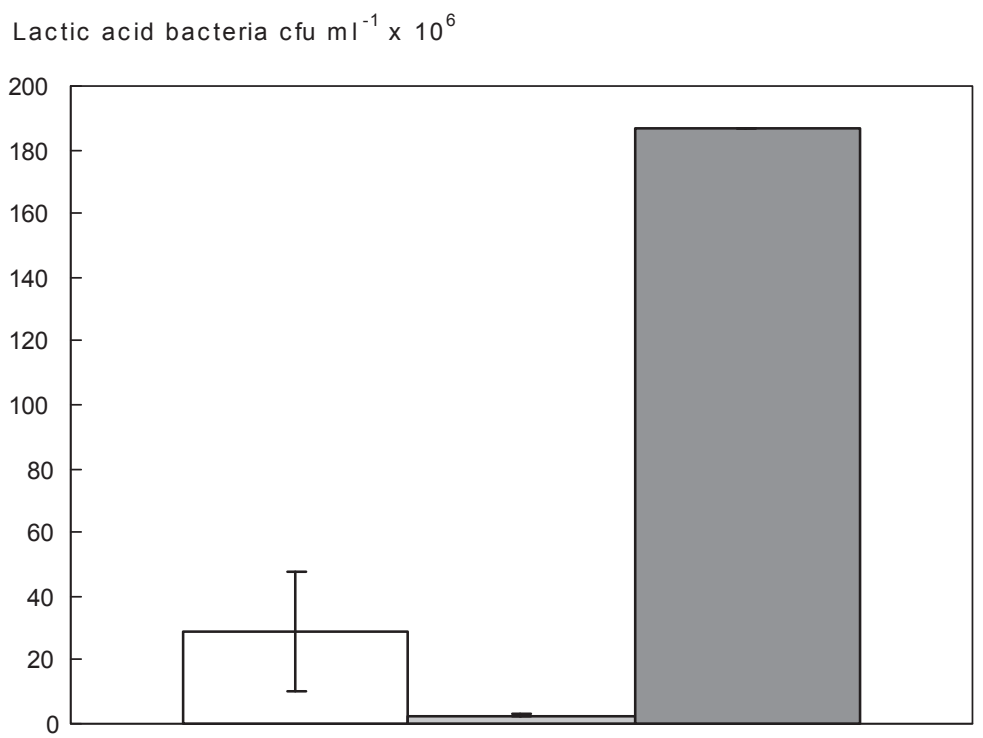

Fig. 2. Number of lactic acid bacteria in sauerkraut juice enumerated immediately after the juice was pressed after spontaneous fermentation at $20^{\circ} \mathrm{C}$ for 20 days using mineral salt. The bars refer to the mean values and standard deviations of bacterial colony forming units (cfu) in three parallel juice samples of juices with three different mineral salt concentrations: $0.8 \%$ mineral salt ( $\square), 1.2 \%$ mineral salt ( $\square$ ) and $1.5 \%$ mineral salt (匹).

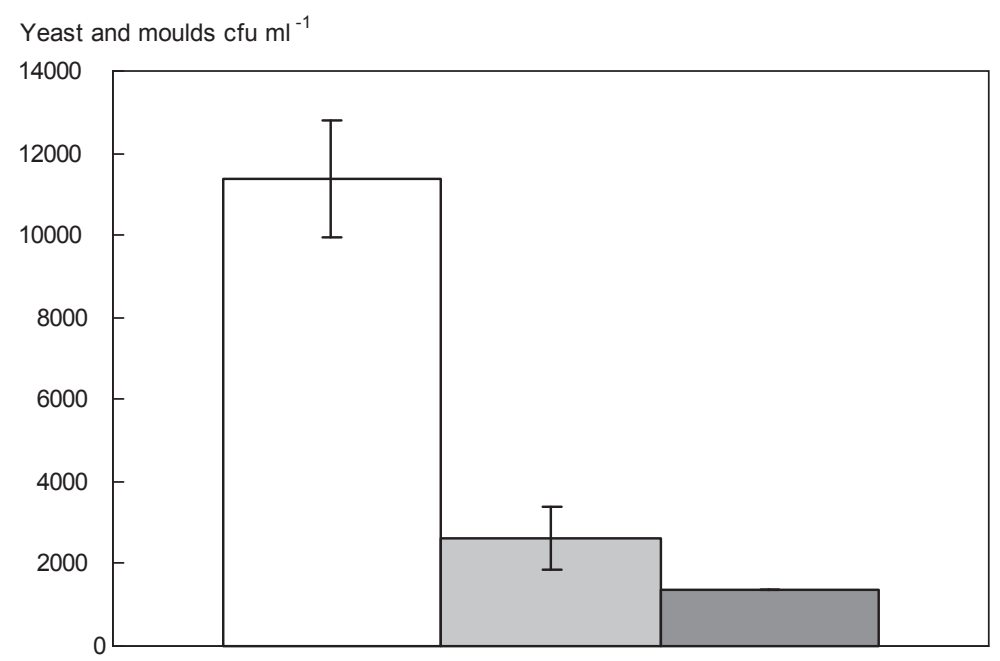

Fig. 3. Number of yeasts and moulds in sauerkraut juice pressed after spontaneous fermentation at $20^{\circ} \mathrm{C}$ using mineral salt. The bars refer to the mean values and standard deviations of colony forming units (cfu) of yeasts and moulds in three parallel juice samples of juices with three different mineral salt concentrations: $0.8 \%$ mineral salt ( $\square), 1.2 \%$ mineral salt ( $\square$ ) and $1.5 \%$ mineral salt ( $\square)$. 
Vol. 20(2011): 169-175.

\section{Garlic and algae supplements}

When $0.8 \%$ mineral salt was used in combination with $0.2 \%$ fresh garlic $\mathrm{pH}$ decreased somewhat more rapidly compared to the treatments with $1 \%$ Vacame algae. The $\mathrm{pH}$ decreased most rapidly at the beginning of the control fermentations with no addition of either garlic or algae (Fig. 4).

The titratable acidity increased more slowly in the treatments with garlic and algae compared to the control fermentations. At the end of the fermentations the titratable acidity was highest in the treatments with garlic (Fig. 4).
The number of yeasts and moulds was lowest in the treatments with fresh garlic and highest in the control fermentations (Fig. 5).

The sensory evaluation of the sauerkraut juices showed that the sauerkraut juices having the best taste were the juices obtained from the treatments with added garlic (3-4 scores) and the control (4-5 scores) sauerkraut juices. The taste panel did not find the juices produced from the fermentations with algae ( 2 scores) very appealing, even though they were considered acceptable.
Fig. 4. Change of $\mathrm{pH}$ (squares) and amount of lactic acid (triangles) during spontaneous fermentation of sauerkraut at $20^{\circ} \mathrm{C}$ using mineral salt with addition of garlic or Vacame algae. The symbols refer to the used mineral salt concentration in combination with garlic or Vacame algae: $0.8 \%$ mineral salt $+0.2 \%$ garlic ( $\square \triangle$ ), $0.8 \%$ mineral salt $+1 \%$ Vacame algae $(\square \Delta)$ and $0.8 \%$ mineral salt with no added garlic nor Vacame algae ( $\mathbf{\Delta}$ , control fermentation). Mean values of two parallel samples are shown.

Fig. 5. Number of yeasts and moulds in sauerkraut juice pressed after spontaneous fermentation at $20^{\circ} \mathrm{C}$ using mineral salt. The bars refer to the mean values and standard deviations of colony forming units (cfu) of yeasts and moulds in three parallel juice samples of three different juices with $0.8 \%$ mineral salt in combination with garlic or Vacame algae: $0.8 \%$ mineral salt $+0.2 \%$ garlic ( $\square$ ), $0.8 \%$ mineral salt $+1 \%$ Vacame algae ( $\square$ ) and $0.8 \%$ mineral salt with no added garlic nor Vacame algae ( $\square$, control fermentation).

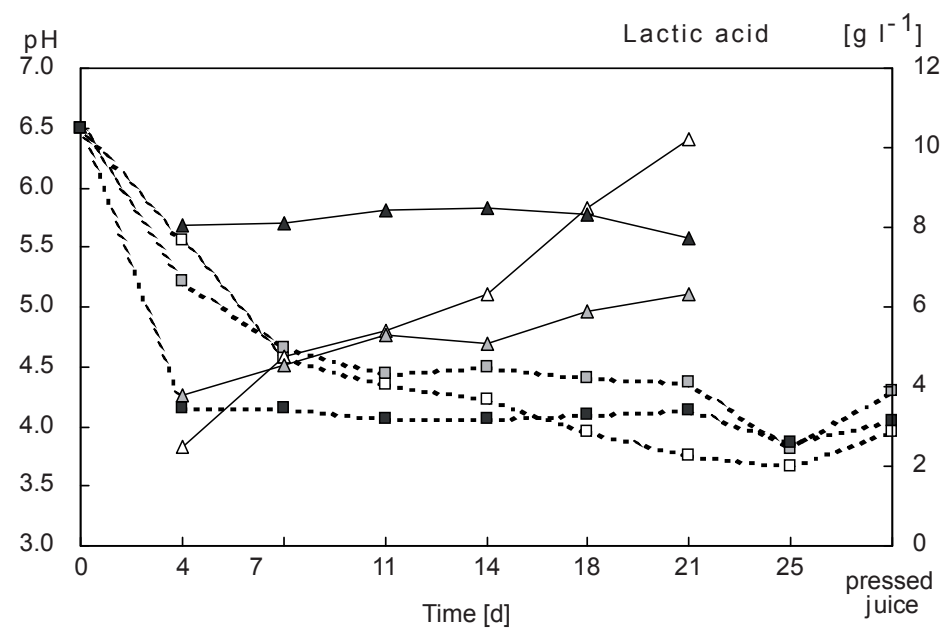

Yeast and moulds cfu $\mathrm{ml}^{-1}$

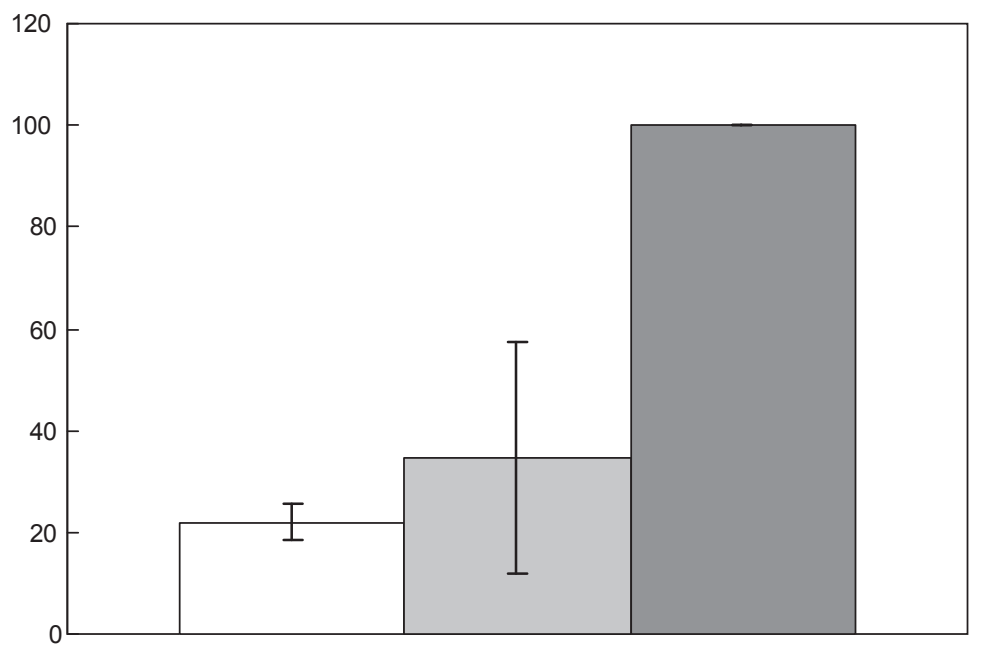


Wiander, B. and Palva, A. Impact of mineral salt, garlic and algae on sauerkraut fermentation

\section{Cabbage slicing}

The $\mathrm{pH}$ decreased rather similarly in all treatments, except for a somewhat slower decrease at the beginning of the treatments in which the cabbage was sliced into a very fine mix (approximately $1 \mathrm{~mm} \times$ $1 \mathrm{~mm}$ ). The titratable acidity increased most in the treatments with the cabbage shredded into a very fine mix (Fig. 6).

The highest yield of pressed sauerkraut juice was obtained from the treatments with the cabbage cut into a very fine mix $(1 \mathrm{~mm} \times 1 \mathrm{~mm})$ being nearly $80 \%$. When the size of the cabbage slices was $2 \mathrm{~mm} \times 10 \mathrm{~mm}$ and $3 \mathrm{~mm} \times 40 \mathrm{~mm}$ the yield of pressed sauerkraut juice was $70 \%$ and $60 \%$ respectively.

\section{Discussion}

The preliminary results of this study show that it is possible to produce sauerkraut and sauerkraut juice by natural fermentation using mineral salt $(0.8 \%$,
$1.2 \%$ and $1.5 \%$ ) with final $\mathrm{NaCl}$ concentrations of $0.5 \%, 0.7 \%$ and $0.9 \%$. All the sauerkraut juices were found to have a smoother taste compared to sauerkraut juices produced by using ordinary salt. However, the preliminary sensory evaluation of the sauerkraut juices showed that the best sensory quality was obtained by fermentation using $0.8 \%$ mineral salt resulting in a very smooth-tasting juice. On the other hand the number of lactic acid bacteria was highest when $1.5 \%$ mineral salt was used in the fermentation trials and the number of yeast and moulds was lowest in these trials. Although the used mineral salt amounts were low the fermentation process proceeded well and the $\mathrm{pH}$ decreased to the desired level, $\mathrm{pH} 3.8$ in a time of 20-25 days. The highest yield of pressed sauerkraut juice was obtained from the treatments where the cabbage was cut into a very fine mix, the cabbage slices being approximately $1 \mathrm{~mm} \times 1 \mathrm{~mm}$.

The preliminary sensory evaluation results show that it is possible to produce sauerkraut and sauerkraut juice with low sodium content with garlic and algae supplements. Consumers who want to consume fermented vegetable products with low sodium content would perhaps find these kinds of products interesting.

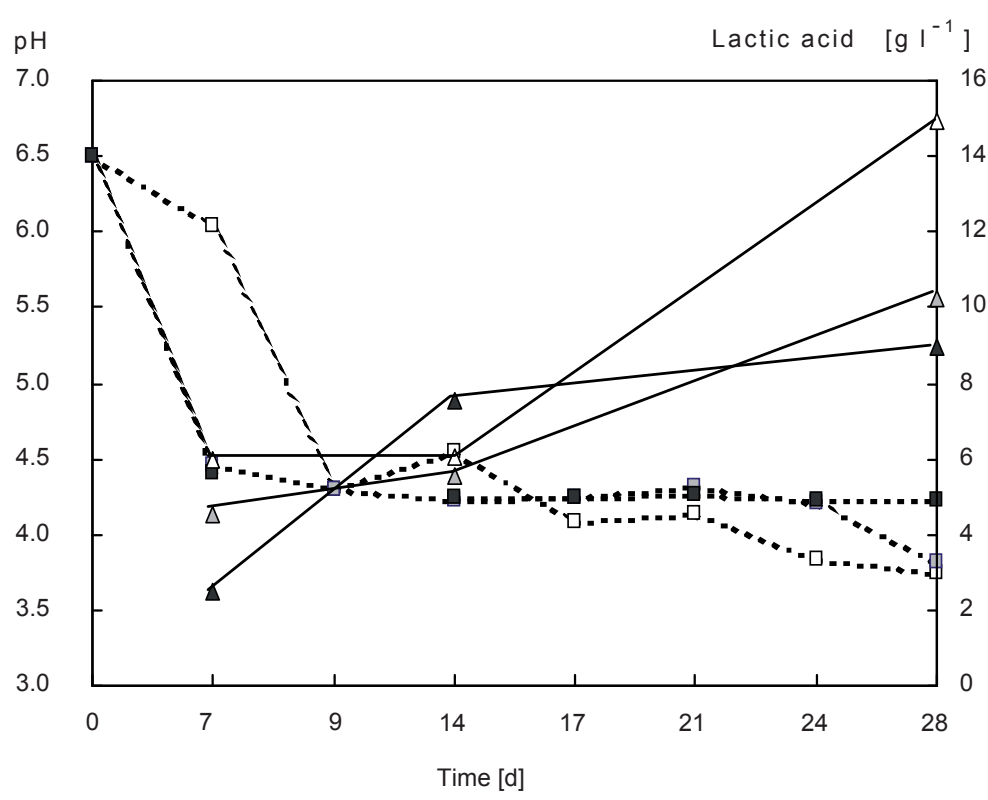

Fig. 6. Change of $\mathrm{pH}$ (squares) and amount of lactic acid (triangles) during spontaneous fermentation of sauerkraut at $20{ }^{\circ} \mathrm{C}$ using $0.8 \%$ mineral salt. The symbols refer to the different sizes of the fermented cabbage slices: $1 \mathrm{~mm}$ x $1 \mathrm{~mm}(\square \triangle$ ), $2 \mathrm{~mm} \times 10 \mathrm{~mm}(\square \Delta)$ and $3 \mathrm{~mm}$ x $40 \mathrm{~mm}$ ( $\boldsymbol{\Delta}$ ). Mean values of two parallel samples are shown. 
Vol. 20(2011): 169-175.

Acknowledgements. The authors are grateful to Dr. Ilkka Palva for participating in this study. We also wish to thank Mrs. Pirjo Satka for technical assistance and Mrs. Heli Vähä-Touru for assistance in preparing the graphics. Furthermore, we are thankful to Arktinen Bio-Lacto Oy for delivering the cabbage needed in the fermentation trials.

\section{References}

Choi, S.-Y., Beuchat, L.R., Perkins, L.M. \& Nakayama, T. 1994. Fermentation and sensory characteristics of kimchi containing potassium chloride as a partial replacement for sodium chloride. International Journal of Food Microbiology 21: 335-340.

Delanoe, R. \& Emard, L.O. 1971. Experimental manufacture of sauerkraut in Quebec. Quebec Laitier et Alimentaire 30: 11-14.

Delclos, M. 1992. Vegetable preservation by a mixed organic acid fermentation. Dissertation Abstracts International -B 52: 4537.

Fleming, H.P. \& McFeeters, R.F. 1985. Residual sugars and fermentation products in raw and finished commercial sauerkraut. New York State Agricultural Experiment Station Special Report 56: 25-29.

Gangopadhyay, H. \& Mukherjee, S. 1971. Effect of different salt concentrations on the microflora and physicochemical changes in sauerkraut fermentation. Journal of Food Science and Technology 8: 127-131.

Hsu, J.Y., Wedral, E.R. \& Klinker, W.J. 1984. Preparation of sauerkraut utilizing hydrolysed protein. United States Patent US4428968.

Johanningsmeier, S.D., McFeeters, R.F., Fleming, H.P. \& Thompson, R.L. 2007. Effects of Leuconostoc mesenteroides starter culture on fermentation of cabbage with reduced salt concentrations. Journal of Food Science 72: M166-M172.
Martinez-Villaluenga, C., Penas, E., Frias, J., Ciska, E., Honke, J., Piskula, M.K., Kozlowska, H. \& Vidal-Valverde, C. 2009. Influence of fermentation conditions on glucosinolates, ascorbigen, and ascorbic acid content in white cabbage (Brassica oleracea var. capitata cv. Taler) cultivated in different seasons. Journal of Food Science 74: C62-C67.

Mayer, K., Pause, G. \& Vetsch, U. 1973. Bildung biogener Amine während der Sauerkrautgärung. Industrielle Obst und Gemüseverwertung 58: 307-309.

Niven, C.F. 1980. Technology of sodium in processed foods: general bacteriological principles, with emphasis on canned fruits and vegetables, and dairy foods. In: Sodium and potassium in foods and drugs, Na \& K Symposium. American Medical Association, USA. p. 45-48.

Oltz, P. \& Hubert, J. C. 1990. Preservation process, especially for fresh seaweeds. French Patent Application FR2637465A1

Owades, J.L. 1991. Method of making salt-free sauerkraut. United States Patent US5064662.

Penas, E., Frias, J., Sidro, B. \& Vidal-Valverde C. 2010. Chemical evaluation and sensory quality of sauerkrauts obtained by natural and induced fermentations at different $\mathrm{NaCl}$ levels from Brassica oleracea var. capitata cv. Bronco grown in eastern Spain. Effect of storage. Journal of Agricultural and Food Chemistry 58: 3549-3557.

Pederson, C.S. 1940. The relation between quality and chemical composition of canned sauerkraut. New York State Agricultural Experiment Station Bulletin 693: 1-15.

Sutabhaha, S., Suttajit, M. \& Niyomca, P. 1992. Studies of aflatoxins in Chiang Mai, Thailand. Kitasato Archives of Experimental Medicine 65: 45-52.

Tolonen, M., Taipale, M., Viander, B., Pihlava, J.-M., Korhonen, H. \& Ryhänen, E.-L. 2002. Plant-derived biomolecules in fermented cabbage. Journal of Agricultural and Food Chemistry 50: 6798-6803.

Trail, A.C., Fleming, H.P., Young, C.T. \& McFeeters, R.F. 1996. Chemical and sensory characterization of commercial sauerkraut. Journal of Food Quality 19: 15-30.

Tuorila, H. \& Hellemann, U. 1993. In Elintarvikkeet aistien puntarissa. University of Helsinki, p. 37, 39 (In Finnish).

Viander, B., Mäki, M. \& Palva, A. 2003. Impact of low salt concentration, salt quality on natural large-scale sauerkraut fermentation. Food Microbiology, 20: 391-395.

Wedral, E.R., Klinker, W.J. \& Hsu, J.Y. 1985. Flavouring process. European Patent EP0106236B1. 